\title{
WEIGHTED ENDPOINT ESTIMATES FOR MULTILINEAR COMMUTATOR OF LITTLEWOOD-PALEY OPERATOR
}

\author{
Changhong Wu AND MENG ZHANG
}

Abstract. In this paper, we prove the weighted endpoint estimates for multilinear commutator of Littlewood-Paley operator.

Mathematics subject classification (2010): 42B20, 42B25.

Keywords and phrases: Littlewood-paley operator, multilinear commutator, Hardy spaces, $B M O\left(R^{n}\right)$.

\section{REFERENCES}

[1] J. Alvarez, R. J. Babgy, D. S. Kurtz And C. PÉReZ, Weighted estimates for commutators of linear operators, Studia Math., 104 (1993), 195-209.

[2] Bui HuY Qui, Weighted Hardy spaces, Math. Nachr., 103 (1981), 45-62.

[3] W. G. CHEN AND G. E. Hu, Weak type $\left(H^{1}, L^{1}\right)$ estimate for a multilinear singular integral operator, Adv. in Math.(China), 30, 1 (2001), 63-69.

[4] R. COIFMAn, R. Rochberg AND G. Weiss, Factorization theorems for Hardy spaces in several variables, Ann. of Math., 103 (1976), 611-635.

[5] J. GARCIA-Cuerva AND J. L. RUBio DE FrAnCIA, Weighted norm inequalities and related topics, North-Holland Math., 116, Amsterdam, 1985.

[6] E. Harboure, C. Segovia And J. L. Torrea, Boundedness of commutators of fractional and singular integrals for the extreme values of $p$, Illinois J.Math., 41 (1997), 676-700.

[7] L. Z. LiU, Weighted weak type $\left(H^{1}, L^{1}\right)$ estimates for commutators of Littlewood-Paley operator, Indian J. of Math., 45 (2003), 71-78.

[8] L. Z. LiU, Weighted Block-Hardy spaces estimates for commutators of Littlewood-Paley operators, Southeast Asian Bull. of Math., 27 (2004), 833-838.

[9] C. PÉREZ AND R. TRUjILlo-GonZALEZ, Sharp weighted estimates for multilinear commutators, J.London Math. Soc., 65 (2002), 672-692.

[10] E. M. STEIN, Harmonic Analysis: real variable methods, orthogonality and oscillatory integrals, Princeton Univ. Press, Princeton NJ., 1993.

[11] A. Torchinsky, Real variable methods in harmonic analysis, Pure and Applied Math., 123, Academic Press, New York, 1986. 